INTER-LEGERE

A MEDIDA PROVISÓRIA 746/2016 E SUAS IMPLICAÇÕES PARA A PERMANÊNCIA E REDIMENSIONAMENTO DA SOCIOLOGIA NO CURRÍCULO DO ENSINO MÉDIO

Francisco Alencar Mota

Antonia Zeneide Rodrigues

\title{
A MEDIDA PROVISÓRIA 746/2016 E SUAS IMPLICAÇÕES PARA A PERMANÊNCIA E REDIMENSIONAMENTO DA SOCIOLOGIA NO CURRÍCULO DO ENSINO MÉDIO
}

\section{THE "MEDIDA PROVISÓRIA" No 746/2016 AND ITS IMPLICATIONS FOR STAYING AND RESIZING SOCIOLOGY IN THE HIGH SCHOOL CURRICULUM}

Francisco Alencar Mota Antonia Zeneide Rodrigues

\section{RESUMO}

A Medida Provisória oㅜ 746, de 23 de setembro de 2016, que reformula o Ensino Médio no país, imposta de forma autoritária pelo governo Temer, representa evidente ameaça à disciplina de Sociologia no atual currículo desse nível de ensino, após um longo processo de consolidação de seus conteúdos, métodos e finalidade por parte dos poderes públicos e dos principais segmentos sociais envolvidos, quando de seu retorno definitivo pela lei $n^{0} \mathbf{1 1 . 6 8 4 / 2 0 0 8}$. Tal ameaça é sentida pelo menos nos seguintes aspectos: sua existência enquanto disciplina, nos termos da lei 11.684/2008; a redução de sua carga horária, os conteúdos ministrados e a competência para sua ministração. Como decorrência, a MP 746/2016 representa igualmente uma ameaça à formação de jovens na faixa etária correspondente, em termos do que essa disciplina representa para a consolidação da democracia, dos direitos humanos e sociais e da promoção da cidadania. O presente trabalho compreende a referida reforma no âmbito do plano de ajuste fiscal do governo, que prioriza a redução das despesas públicas, às expensas do bem estar social, de forma a atender muito 
INTER-LEGERE

A MEDIDA PROVISÓRIA 746/2016 E SUAS IMPLICAÇÕES PARA A PERMANÊNCIA E REDIMENSIONAMENTO DA SOCIOLOGIA NO CURRÍCULO DO ENSINO MÉDIO

Francisco Alencar Mota

Antonia Zeneide Rodrigues

mais aos interesses econômicos dominantes do que mesmo aos interesses dos principais sujeitos da educação - educandos, suas famílias, professores e dirigentes escolares, e a própria sociedade em geral, consistindo-se, portanto, numa ameaça aos valores democráticos e da cidadania.

Palavras-chave: Brasil - Medida Provisória № 746/2016. Sociologia. Ensino Médio.

\section{ABSTRACT}

The "Medida Provisória" No. 746, of September 23, 2016, which reformulates the high school education sistem in the country, imposed in an authoritarian manner by Temer government, is such a evident threat to Sociology discipline in the current curriculum of this school level, after an entire consolidation process of its contents, methods and purpose by the public authorities and the main social segments involved, on the occasion of his definitive return by law No. 11,684 / 2008. Such a threat is felt at least the following aspects: its existence as a discipline under the law 11,684 / 2008; reducing their time of durability, the content taught and competence to their Teaching. As a result, the MP 746/2016 also poses a threat to the formation of young people in the corresponding age group, in terms of what this discipline is for the consolidation of democracy, human and social rights and the promotion of citizenship. The work cover on this reformation within the government's fiscal adjustment plan, that prioritizes the reduction of public spending, at the expense of social welfare, in order to answer more to the dominant economic interests than even the interests of the main education subjects - students, their families, teachers and school leaders, and society itself generally consisting, therefore, a threat to democratic values and citizenship. 
INTER-LEGERE

A MEDIDA PROVISÓRIA 746/2016 E SUAS IMPLICAÇÕES PARA A

PERMANÊNCIA E REDIMENSIONAMENTO DA SOCIOLOGIA NO

CURRÍCULO DO ENSINO MÉDIO

Francisco Alencar Mota

Antonia Zeneide Rodrigues

Keywords: Brazil - "Medida Provisória no.746/2016". Sociology. High school.

\section{INTRODUÇÃO}

No dia 22 de setembro de 2016, a sociedade brasileira foi surpreendida com o anúncio, via principais veículos da imprensa, pelo próprio Ministro da Educação, Sr. José Mendonça Bezerra Filho, da Medida Provisória 746/2016, publicada no Diário Oficial da União, no dia seguinte, que reforma o Ensino Médio no Brasil. O anúncio causou a amplos setores sociais uma repulsa por diversas razões que pretendemos explicitar no presente trabalho, ainda que focando, mais especificamente, as implicações para a disciplina de Sociologia no currículo do Ensino Médio com a referida Reforma.

Refletiremos desde a maneira como esta Reforma está sendo implementada, através de uma Medida Provisória, como também seus conteúdos, princípios e fundamentos, buscando compreendê-la em perspectiva mais ampla que envolve, em termos políticos, a chegada ao poder de "novas" elites, como consequência do processo de impeachment da então presidenta Dilma Rousseff, o controle da sociedade e a implantação de medidas diversas com vista à suposta reorganização e retomada do desenvolvimento econômico do país, além de outras em que a reforma do Ensino Médio é apenas um capítulo.

Defenderemos aqui, no que concerne mais especificamente ao destino da disciplina de Sociologia no currículo do Ensino Médio que a mesma se encontra sob evidente ameaça tanto no que se refere à quantidade de horas reservadas para a sua ministração como também no formato disciplinar em que é atualmente oferecida, além dos próprios conteúdos, tendo em vista que a mesma poderá ser ministrada por profissionais sem formação específica, com sérios prejuízos à própria formação educacional e cidadã dos alunos do Ensino Médio. 
A MEDIDA PROVISÓRIA 746/2016 E SUAS IMPLICAÇÕES PARA A PERMANÊNCIA E REDIMENSIONAMENTO DA SOCIOLOGIA NO CURRÍCULO DO ENSINO MÉDIO

Francisco Alencar Mota

Antonia Zeneide Rodrigues

\section{SÍNTESE DA TRAJETÓRIA DA SOCIOLOGIA NOS CURRÍCULOS DO ENSINO MÉDIO}

Pretendemos aqui, tão somente, uma síntese da trajetória da disciplina de Sociologia no currículo do Ensino Médio, poupando o leitor especializado deste cansaço repetitivo e indicando aos leitores não familiarizados com o tema, nas referências, uma literatura mais direcionada. Assim o fazendo, nosso objetivo é situarmos o tema central desse trabalho sob uma perspectiva histórica, convictos de que o retrocesso que afirmamos existir em função das ameaças à Sociologia trazidas pela Reforma em questão é mais uma repetição das voltas ao poder de um segmento das elites políticas e econômicas brasileiras que historicamente vêm manipulando a educação aos seus interesses excludentes, usurpações essas que tem sofrido revezes quando a democracia prevalece, em função das lutas sociais e, no caso em apreço, os movimentos sociais em prol da educação. As ameaças a esta disciplina trazidas pela Reforma em questão, a despeito de serem negadas nos discursos dos idealizadores, promotores e executores da mesma, que insistem em dizer que essa disciplina não sofrerá prejuízos, o contrário é o que se pode constatar a partir da própria letra da lei e dos fundamentos principiológicos que norteiam o próprio governo que emergiu do processo de impeachment da então presidenta Dilma Rousseff.

Nessa direção, afirmamos que tal ameaça se coaduna com todas as outras tentativas no mesmo sentido, em momentos históricos no passado, a exemplo dos regimes ditatoriais de 1937, conhecido como Estado Novo, e a partir de 1964, através do Golpe Militar, para citar alguns exemplos emblemáticos, de forma que a obrigatoriedade da Sociologia no currículo do Ensino Médio fora sempre retirada quando, por ocasião de governos autoritários, militar ou mesmo civil, de onde uma coisa podemos concluir: que o tema da obrigatoriedade ou não da Sociologia no currículo do Ensino Médio é pertinente ao tema da própria democracia e da cidadania, assim como, de outra forma, as 
A MEDIDA PROVISÓRIA 746/2016 E SUAS IMPLICAÇÕES PARA A PERMANÊNCIA E REDIMENSIONAMENTO DA SOCIOLOGIA NO CURRÍCULO DO ENSINO MÉDIO

Francisco Alencar Mota

Antonia Zeneide Rodrigues

lutas em prol desta obrigatoriedade coincidem com as lutas políticas pela própria democratização do país.

Limitaremo-nos, porém, às reformas oficiais do ensino a partir da criação do Ministério da Educação no Brasil, em 1931, e a organização do sistema de ensino para todo o país, salientando, no entanto, que o tema vem já desde a primeira República. Até mesmo porque, antes de 1930, a grande maioria das reformas sequer tinha alcance nacional, e se restringia a uma ou outra escola ou mesmo federação. Assim, a Sociologia foi obrigatória em 1931, sob o primeiro governo de Getúlio Vargas, e respectivo Ministro da Educação recém empossado, Francisco Campos, mas retirada em 1937 quando do Estado Novo, sob novo governo, agora sob regime ditatorial; volta a ser retirada quando do Golpe Militar de 1964, e substituída em 1971 (Lei 5.692/71, que instituiu a reforma do Ensino Médio) por disciplinas de ideologia conservadora tais como Educação Moral e Cívica, e Organização Social e Política do Brasil. Com a Lei de Diretrizes e Bases da Educação Nacional (Lei 9.394/1996), atual LDB, a Sociologia volta a ser obrigatória embora que não se ao formato de disciplina, mas a "conhecimentos de Filosofia e Sociologia", o que suscitou uma ampla discussão em função da ambiguidade interpretativa - se tais conteúdos deveriam ser necessariamente ministrados como disciplina ou de forma transversal, podendo tais conteúdos estarem presentes em outras disciplinas. Aliás, essa mesma interpretação volta à tona agora com a Reforma em questão. Somente em 2008, como consequência de muitas lutas, foi aprovada a lei no 11.684/2008, que estabeleceu a seguinte redação pondo fim à controversa ao inciso N, do artigo 36 da LDB: "serão incluídas a Filosofia e a Sociologia como disciplinas obrigatórias (grifo nosso) em todas as séries do Ensino Médio".

A partir de então, tanto os sistemas de ensino como as comunidades escolares e as entidades representativas da área inauguraram um amplo processo de discussão acerca dos conteúdos e métodos de ensino da referida disciplina a ponto de podermos dizer que, até a data da publicação da Medida 
A MEDIDA PROVISÓRIA 746/2016 E SUAS IMPLICAÇÕES PARA A PERMANÊNCIA E REDIMENSIONAMENTO DA SOCIOLOGIA NO CURRÍCULO DO ENSINO MÉDIO

Francisco Alencar Mota

Antonia Zeneide Rodrigues

Provisória em questão no $\mathrm{DOU}$, tal processo já se encontrava em plena consolidação, ficando todo ele agora ameaçado em função da referida Reforma, como demonstraremos.

Destaque-se, ainda, a trajetória mais recente da Sociologia no Ensino Médio, a partir de 1982, quando a lei 7.044/1982 alterou a lei 5.692/71 (última reforma do Ensino Médio antes da MP em questão), conferindo aos sistemas de ensino maior liberdade na definição dos conteúdos escolares. Desde então deflagrando-se um processo não uniforme de reinserção da Sociologia no Ensino Médio no âmbito dos próprios estados, quer através de normas dos seus conselhos estaduais de educação, como também de suas assembleias legislativas. Constituiu-se um marco reinaugural, nesse sentido, uma Resolução da Secretaria de Educação do Estado de São Paulo, em 1984, fazendo retornar a disciplina de Sociologia ao Ensino Médio, processo esse que até 2007 se repetiu, ainda que de forma desigual, em outros estados, até a lei n 11.684/2008, que pôs fim a todos os entraves que obstaculizavam tal consolidação, ficando de vez e, em nível nacional, reintroduzida a disciplina de Sociologia no currículo do Ensino Médio.

Nesse ínterim, uma série de documentos foram elaborados pelo Ministério da Educação e Cultura que norteavam os fundamentos e objetivos da educação no Ensino Médio, com destaque para as Diretrizes Curriculares Nacionais para o Ensino Médio (DCNEM), Parâmetros Curriculares Nacionais Para o Ensino Médio (PCNEM) e Orientação Curricular Nacional Para o Ensino Médio (OCNEM), fazendo referências à disciplina de Sociologia. Este último, ao qual foi complementado pelas Orientações Curriculares Complementares, diferentemente dos demais, adentra mais diretamente o objetivo dessa disciplina nesse referido nível de ensino, voltado para o desenvolvimento do senso crítico da realidade social e para a cidadania, sobretudo quanto às desigualdades sociais, os processos produtivos e tecnológicos, as transformações sociais, o 
A MEDIDA PROVISÓRIA 746/2016 E SUAS IMPLICAÇÕES PARA A PERMANÊNCIA E REDIMENSIONAMENTO DA SOCIOLOGIA NO CURRÍCULO DO ENSINO MÉDIO

Francisco Alencar Mota

Antonia Zeneide Rodrigues

pensar científico e a formação humanística, conferindo ao educando a perspectiva de humanização do próprio homem.

\section{A SOCIOLOGIA NO ENSINO MÉDIO EM FACE DO PENSAMENTO SOCIAL BRASILEIRO}

As reivindicações e conquistas mais recentes concernentes à Sociologia no Ensino Médio são corolário de reivindicações mais antigas, sobretudo a partir da década de 1930 e seguintes, com as mudanças no cenário político, econômico e sociocultural do país. Nesse sentido, destacam-se movimentos em prol da educação, como o dos Pioneiros da Educação Nova, em âmbito nacional, reivindicando uma educação pública, gratuita, unificada, igualitária e voltada para o desenvolvimento do país; as reformas do ensino em diversos estados, como consequência desse movimento; as reivindicações em torno da Lei de Diretrizes e Bases para a educação, bem como do Plano Nacional de Educação, dentre outros, no contexto do desenvolvimento socioeconômico e cultural, da institucionalização da educação e de um projeto de nação ${ }^{1}$. A educação emerge como uma questão nacional a ser resolvida, não somente em termos da superação no analfabetismo, mas de uma educação que atendesse aos imperativos de uma sociedade em mudanças.

É nesse sentido que o ensino das Ciências Sociais, e, em particular, a Sociologia emerge como objeto de reflexão em meio a esse conjunto de fatores que a nova sociedade brasileira estava lidando, sobretudo educadores, mas também diversos segmentos sociais, e, obviamente, em face do pensamento social brasileiro.

\footnotetext{
${ }^{1}$ Sobre o que pensavame defendiam para a educação os integrantes desse movimento recomendamos a leitura dos dois manifestos, redigidos por Fernando de Azevedo, mas assinados e divulgados por seus principais integrantes: o primeiro, datado de 1932, enquanto que o segundo, datado de 1959. Sobre o Movimento recomendamos os trabalhos de Paulo Ghiraldelli Jr e Otaíza de Oliveira Romanelli, nas referências.
} 
A MEDIDA PROVISÓRIA 746/2016 E SUAS IMPLICAÇÕES PARA A PERMANÊNCIA E REDIMENSIONAMENTO DA SOCIOLOGIA NO CURRÍCULO DO ENSINO MÉDIO

Francisco Alencar Mota

Antonia Zeneide Rodrigues

A Sociedade Brasileira de Sociologia - SBS, desde seu primeiro Congresso, em 1954, vem promovendo amplos debates acerca da disciplina de Sociologia nos currículos escolares, e, não por outro motivo, tal preocupação se intensificou por ocasião dos amplos espaços de discussão desse tema a partir de 2008, quando do retorno mais recente da Sociologia nos currículos do Ensino Médio. Desde então, seus congressos passaram a se constituir em palcos desse debate de forma mais qualificada, de onde se explica a criação de grupos de trabalhos, comissões específicas em seus congressos, para a discussão do papel que a recém reintroduzida disciplina nos currículos escolares deveria ter, assim como os conteúdos e métodos de ensino².

Por ocasião do discurso de encerramento do I Congresso da Sociedade Brasileira de Sociologia, seu então presidente, o sociólogo Fernando de Azevedo, em sua conferência de encerramento, faz referência ao estudo feito por Arbousse Bastide, ainda que sob uma perspectiva crítica, sobre o papel da Sociologia no então denominado ensino secundário (correspondente ao Ensino Médio, hoje). Comenta que o ensino de Sociologia é de suma importância para a formação do espírito dos jovens, disso dependendo a própria qualidade do ensino dessa disciplina, em nível superior, de onde resulta a grande responsabilidade das então faculdades de Filosofia, Ciências e Letras, a quem cabia à época a formação de professores para essa respectiva área. Para o autor, a qualidade das especializações científicas, em nível superior, depende do trabalho científico também no nível secundário, em caráter propedêutico e cultural, de ensino geral, ao lado dos conteúdos literários. Assim, preocupado com a formação científica já no âmbito do ensino secundário, sobretudo no que diz respeito ao raciocínio lógico e o método indutivo, como forma de se entender a realidade social, o autor vê como principal contribuição da Sociologia no nível médio, as condições básicas desta formação a se aprimorar no nível superior.

\footnotetext{
${ }^{2}$ Destaque-se ainda as discussões e lutas políticas sobre a Sociologia no Ensino médio, no âmbito da Federação Nacional dos Sociólogos do Brasil (FNSB) e Sindicato dos Sociólogos do Estado de São Paulo, sobre cuja memória indicamos o texto organizado por Lejeune Mato Grosso de Carvalho, nas Referências. 
A MEDIDA PROVISÓRIA 746/2016 E SUAS IMPLICAÇÕES PARA A PERMANÊNCIA E REDIMENSIONAMENTO DA SOCIOLOGIA NO CURRÍCULO DO ENSINO MÉDIO

Francisco Alencar Mota

Antonia Zeneide Rodrigues

Em outras palavras, seria o mesmo que propiciar à nossa juventude o juízo crítico da realidade social para que ela se habitue a ver a realidade com rigor analítico e amor ao que é justo e verdadeiro.

\begin{abstract}
Entre as ciências, cujo ensino seguramente orientado pode contribuir à formação do espírito e para as quais os sábios e os homens de nosso tempo pedem, com insistência, na educação da juventude, o papel que elas já têm na vida, figura certamente a Sociologia, que além das virtudes educativas, comuns a todas, e outras que lhe são peculiares $e$ se prendem à sua própria natureza e à especificidade de seu objeto e de seus métodos, concorre, como nenhuma outra, para despertar, no indivíduo, a consciência da vida social de seu papel na sociedade e dos problemas sociais. (AZEVEDO, 2003, p. 41)
\end{abstract}

Igualmente digna de referência, é a análise de Florestan Fernandes, que refletiu e sistematizou acerca do ensino dessa disciplina no currículo da escola secundária, em cujo contexto histórico a mesma estava praticamente limitada às escolas normais. E assim procedeu a partir de um balanço das propostas de diversos autores, dentre os quais, Karl Mannheim, Arbousse-Bastide, Antonio Cândido, Rocha Pinto, ainda que parcialmente críticos de todos esses, por, segundo ele, limitarem, cada um a seu modo, a discussão em termos de abordagens de uma filosofia educacional ou de uma política educacional, ao invés de uma abordagem sociológica, propriamente dita, sendo essa a tarefa que se propôs, como fundamento para as conclusões a que chegou.

O autor parte de uma análise sociológica crítica do próprio sistema de ensino secundário no país, em meio às contradições e atrasos culturais do país, afirmando ser tal sistema estático, decorrente de amarras a mentalidades tradicionais, voltado unicamente para a manutenção da ordem social, e, por isso, incapaz de "tornar-se um instrumento consciente de progresso social" (FERNANDES, p. 98). Assim sendo, qualquer que seja a possibilidade de a Sociologia vir a fazer parte do currículo da escola secundária dever-se-á levar em consideração tal fato, bem como a análise da realidade social, julgando melhor proposta a de definir o papel dessa disciplina estando voltado "para a 
A MEDIDA PROVISÓRIA 746/2016 E SUAS IMPLICAÇÕES PARA A PERMANÊNCIA E REDIMENSIONAMENTO DA SOCIOLOGIA NO CURRÍCULO DO ENSINO MÉDIO

Francisco Alencar Mota

Antonia Zeneide Rodrigues

formação de atitudes cívicas e para a constituição de uma consciência política definida em torno da compreensão dos direitos e deveres dos cidadãos". (FERNANDES, 2011, p.103)

Florestan Fernandes defende a inserção da Sociologia no currículo da escola secundária, porém, o fazendo não por mero interesse corporativo desta ciência, mas em função das possibilidades que ela encerra, no contexto histórico e cultural do país, exigindo-se como condição prévia uma clareza dessas possibilidades e as condições em que isso seria possível. Assim, tal inserção não deveria ser unicamente em função das demandas dos níveis superiores, mas em função do papel que a Sociologia (ou as ciências sociais) desempenharia quanto a uma visão crítica e progressiva da sociedade.

Enfim, o autor, que sempre teve a educação escolar no centro de suas reflexões, apregoava que o ensino de Sociologia nos currículos da escola não deveria se consistir na transmissão de conteúdos aprendidos, mas sobretudo de uma reflexão que possibilite orientar a prática social dos educandos com vista a uma compreensão da realidade social e do papel da própria escola no contexto das mudanças sociais. Destacava a importância do ensino de Sociologia na escola secundária para a formação da cidadania, propiciando ao aluno refletir e atuar de forma crítica diante dos temas da sociedade, como forma de participação democrática no curso do desenvolvimento social e econômico.

\section{A MEDIDA PROVISÓRIA 746/2016: ESPÉCIE JURÍDICA, FUNDAMENTOS PRINCIPIOLÓGICOS E CONTEÚDOS}

A Reforma do Ensino Médio em análise foi anunciada à sociedade brasileira como uma Medida Provisória (MP 746/2016), no dia 22 de setembro de 2016, e publicada no Diário Oficial da União, no dia seguinte, tendo sofrido críticas de diversos segmentos da sociedade tanto quanto aos seus conteúdos 
INTER-LEGERE

A MEDIDA PROVISÓRIA 746/2016 E SUAS IMPLICAÇÕES PARA A PERMANÊNCIA E REDIMENSIONAMENTO DA SOCIOLOGIA NO CURRÍCULO DO ENSINO MÉDIO

Francisco Alencar Mota

Antonia Zeneide Rodrigues

como também pela espécie normativa escolhida pelo Governo para implementála.

É importante esclarecer - com o objetivo de compreendermos melhor os impactos e convulsões sociais causados com o anúncio da MP em questão - o que é uma Medida Provisória. Esta é uma espécie normativa (ato normativo), previsto na Constituição Federal de 1988, proposto e elaborado pelo Presidente da República e encaminhado imediatamente ao Congresso Nacional (Senado Federal e Câmara Federal) para, em um prazo previsto de 60 dias (renovável por igual período), e em dois turnos de votação, ser apreciada por cada uma dessas casas legislativas, podendo ou não ser aprovada parcial ou totalmente, submetendo-se a ritos previamente estabelecidos em lei e nos regimentos de cada uma dessas casas legislativas (FERNANDES, 2014; PIRES, 2013). Tal espécie normativa tem, dentre suas principais características, versar sobre questões de relevância e urgência, tendo sido já definido pelo Supremo Tribunal Federal - STF que a não caracterização destes critérios tornará uma medida provisória inconstitucional. Além do que, diferentemente de um projeto de lei ordinária, que não tem prazo fixo para ser aprovado, atravessando discussões mais amplas nos órgãos parlamentares, geralmente envolvendo os diversos segmentos sociais, e só produzindo efeitos depois de aprovado, sancionado e publicado, podendo até, por ocasião de sua publicação, estabelecer, ainda, prazos especiais (vacatio legis) para que entre no ordenamento jurídico, uma Medida Provisória tem prazos fixos e curtos, como já mencionado; impedindo, por isso, uma discussão mais ampla, e o que é mais agravante, produz efeito imediato desde a sua publicação no DOU, mesmo que esteja ainda em trâmite no Congresso. Ocorrendo sua aprovação a mesma será definitivamente transformada em lei.

Em caso de não ser aprovada ou não ser votada no prazo estabelecido, a MP perde os seus efeitos ex tunc (ou seja, de forma retroativa à data de sua publicação). Por outro lado, em sendo aprovada, total ou parcialmente, isto é, 
INTER-LEGERE

A MEDIDA PROVISÓRIA 746/2016 E SUAS IMPLICAÇÕES PARA A PERMANÊNCIA E REDIMENSIONAMENTO DA SOCIOLOGIA NO CURRÍCULO DO ENSINO MÉDIO

Francisco Alencar Mota

Antonia Zeneide Rodrigues

com modificações, estas se submeterão, ainda, a um parecer do Presidente da República, que tem poder de veto sobre as referidas alterações, devendo tal veto se submeter, por sua vez, a uma nova apreciação do Congresso Nacional, podendo ou não ser derrubado, o que definirá com qual redação final uma medida provisória será, finalmente transformada em lei.

De acordo com o exposto, a reforma do Ensino Médio proposta pela Medida Provisória já é uma realidade, ainda que alguns de seus principais conteúdos estejam ainda sendo definidos, à revelia da sociedade e dos principais segmentos sociais envolvidos, em contraposição aos princípios democráticos assegurados em nossa Constituição Federal, e a exemplo das políticas educacionais levadas a cabo em nossa histórica por governos autocráticos militares ou civis.

Com relação aos seus fundamentos principiológicos é mister salientar que a MP 746/16 deve ser compreendida no conjunto das diversas medidas que 0 governo Temer tem anunciado e tomado sob o pretexto duvidoso de equilibrar as contas públicas, estancar o desemprego e a inflação, e retomar o crescimento econômico. Tais medidas se coadunam com o programa do governo do PMDB, datado de 29 de outubro de 2015, denominado "Uma Ponte para o Futuro", e que traça as linhas gerais das ações que seriam postas em práticas quando no poder, o que só aconteceria mediante o processo de impeachment da então presidente, como de fato aconteceu, consistindo-se no mais recente golpe político na república brasileira. $O$ documento é essencialmente marcado pela proeminência fiscal de forma autônoma, comum aos governos que impuseram ao social o ônus da crise econômica, penalizando diversos segmentos sociais, sobretudo os trabalhadores da esfera privada e pública pelas crises que o capitalismo não conseguira até o presente momento solucionar. E invertendo o que diversos países capitalistas, sobretudo europeus, que alcançaram melhores resultados econômicos, elegeram como investimentos públicos e social, em despesas a serem suprimidas em vistas à retomara da economia às expensas 
A MEDIDA PROVISÓRIA 746/2016 E SUAS IMPLICAÇÕES PARA A PERMANÊNCIA E REDIMENSIONAMENTO DA SOCIOLOGIA NO CURRÍCULO DO ENSINO MÉDIO

Francisco Alencar Mota

Antonia Zeneide Rodrigues

do social. O Documento elege como prioridades a questão fiscal, orçamentária, previdenciária, dos juros e da dívida pública, em flagrante evidência de que a governança deverá estar sobretudo voltada prioritariamente para a saúde dos aspectos fiscais para o que o investimento no social se constitui em um grande empecilho, devendo subsumir-se aos interesses maiores dos indicadores financeiros do País.

É nesse sentido que se compreende o conjunto das medidas propostas pelo Governo Temer, elaboradas e aprovadas de forma célere, sem qualquer discussão ou participação da sociedade e dos segmentos sociais mais envolvidos. E, ainda, sem que grande parte de seus conteúdos tenham sido definidos, como a própria Reforma do Ensino Médio. Destaque-se que a maioria das reformas e medidas pretendidas pelo atual governo depende de alterações na legislação, criação de novas leis, ou mesmo de mudanças na Constituição Federal, daí, neste último caso, as propostas de emendas à Constituição Federal - PECs, que, a despeito de exigir um rigor maior para serem aprovadas, com um quórum qualificado de votação no Congresso ( $3 / 5$ dos membros de cada uma das casas, em dois turnos de votação), o governo conta com amplo apoio parlamentar, coincidente com o mesmo apoio que se uniu em torno do processo de impeachment da então presidente Dilma, daí a pressa que o Governo tem de aprová-las, sabendo que poderá não mais contar com essa ampla gama de apoio em função de uma série de fatos que se avizinham. ${ }^{3}$

Além da Reforma do Ensino Médio em questão, já se encontra no Senado Federal para aprovação também em dois turnos nessa Casa, tendo já sido aprovada na Câmara dos Deputados, a PEC 241/16 (transformada em PEC

\footnotetext{
3 Dentre estes fatos, destaco: a impopularidade das próprias medidas, que tem se transformados em manifestações de revoltas pelo país; as disputas e negociações visando as eleições presidenciais em 2018, bem como as eleições para a presidência da Câmara Federal, prevista para o início de 2017, podendo dividir a base do governo; as investigações em torno da Lava Jato, focando agora membros chaves dos partidos de apoio do governo, do que serve de exemplo o próprio presidente do Senado Federal, Renan Calheiros, de cujo apoio o governo precisa para aprovar as medidas; o acordo de delação premiada do Ex Deputado Eduardo Cunha, mais especificamente, que ameaçou envolver nomes ligados ao governo.
} 
A MEDIDA PROVISÓRIA 746/2016 E SUAS IMPLICAÇÕES PARA A PERMANÊNCIA E REDIMENSIONAMENTO DA SOCIOLOGIA NO CURRÍCULO DO ENSINO MÉDIO

Francisco Alencar Mota

Antonia Zeneide Rodrigues

55/2016), denominada "PEC dos gastos públicos", tendo em vista o congelamento dos gastos públicos e dos salários dos servidores públicos por vinte anos, reajustáveis somente pela inflação dos últimos doze meses. E o que é mais agravante, a desvinculação desses gastos com o crescimento da economia, ficando patente a visão que o governo possui quanto a tratar o social desatrelando-o da economia, de forma que, mesmo a economia crescendo, o social deverá sofrer um decréscimo, o que possibilitará o aumento da pobreza, da concentração de renda e da exclusão social no País. Também as reformas previdenciária e trabalhista pré-anunciadas estão sendo elaboradas sob o mesmo pressuposto de arrocho das classes trabalhadoras, com o aumento do tempo de trabalho e de contribuição no caso da reforma da previdência, e a flexibilização do trabalho, no caso da reforma trabalhista, como forma de desonerar o Capital de parte das responsabilidades sociais trabalhistas.

No que concerne aos conteúdos da MP 746/16, destacaremos os seguintes: a Reforma retira a obrigatoriedade de diversas disciplinas escolares, conquistadas após ampla discussão e lutas sociais envolvendo os principais segmentos sociais, e julgadas necessárias a uma formação integral sólida e de qualidade, tais como: Filosofia, Sociologia, Artes, Educação Física, História, Geografia, Química, Biologia, Física, Espanhol. De fato, apenas Português, Matemática e Inglês são as únicas disciplinas obrigatórias (as duas primeiras, nos três anos). Isso significa que as demais estão sob o risco de não mais permanecerem como componentes curriculares do Ensino Médio, ou, em permanecendo, de serem ofertadas desigualmente em todo o território nacional pelos sistemas estaduais de ensino. No que concerne à Sociologia, mais especificamente, esta, juntamente com a Filosofia, volta ao currículo do Ensino Médio com a Lei de Diretrizes e Bases da Educação Nacional, e, sobretudo, com a Lei 11.684 , de 2008, que estabeleceu o formato de disciplina, após ampla discussão acerca do art. 36 da LDB, tendo havido diferentes interpretações a esse respeito, como destacamos. 
A MEDIDA PROVISÓRIA 746/2016 E SUAS IMPLICAÇÕES PARA A PERMANÊNCIA E REDIMENSIONAMENTO DA SOCIOLOGIA NO CURRÍCULO DO ENSINO MÉDIO

Francisco Alencar Mota

Antonia Zeneide Rodrigues

Mesmo que o Governo afirme, como tem feito insistentemente, que nenhuma dessas disciplinas serão prejudicadas, permanecendo os seus conteúdos na Base Nacional Comum Curricular - BNCC (ainda a ser definida), não se tem garantia nenhuma dessa permanência. Sobretudo tendo-se em conta a proposta da Reforma em flexibilizar seus conteúdos podendo os mesmos serem ministrados sob um formato diferente do que o de disciplina. Além do que a chamada parte obrigatória, coincidente com a Base Nacional Comum Curricular - BNCC, que ficará a cargo do Ministério da Educação, corresponde a apenas a primeira metade da carga horária total do Ensino Médio, ficando a outra metade a cargo dos sistemas de ensino (secretarias estaduais de educação), violando igualmente o princípio de autonomia escolar e liberdade de escolha do aluno. Portanto, está patente a redução drástica do ensino de Sociologia (como de outras disciplinas), como também a não mais garantia de seus conteúdos continuarem a ser ministrados em forma de disciplina, ficando a lei 11. 684/2008 revogada pela MP 746/2016, com sérios prejuízos à formação do educando.

A possibilidade de redução drástica da carga horária de Sociologia (como também de outras disciplinas), ou mesmo de sua inexistência, é patente, ainda, considerando-se, além da disposição do Ministério da Educação em não ofertar conteúdos que não sejam de Português, Matemática e Inglês no formato de disciplina, o fato de, segundo a própria Medida Provisória, os sistemas de ensino não possuírem a obrigatoriedade de ofertar concomitantemente todas as áreas do conhecimento (Linguagens, Matemática, Ciências da Natureza, Ciências Humanas e Formação Técnica e Profissional), podendo limitar essa oferta a apenas uma delas, ferindo, assim, o direito à educação entendido como acesso à totalidade dos conhecimentos escolares, como patrimônio cultural, salvo quando lhes é disponível a opção pessoal, e não dos sistemas de ensino, em violação também ao princípio da autonomia da escola e de aprendizado do aluno. 
A MEDIDA PROVISÓRIA 746/2016 E SUAS IMPLICAÇÕES PARA A PERMANÊNCIA E REDIMENSIONAMENTO DA SOCIOLOGIA NO CURRÍCULO DO ENSINO MÉDIO

Francisco Alencar Mota

Antonia Zeneide Rodrigues

No que tange a formação docente, esta está posta no princípio da formação específica, tendo isso sido consequência de discussões e acordos já consolidados. Em acabando o formato de disciplinas, como sugere os idealizadores da Reforma, voltar-se-á ao período histórico, já há muito ultrapassado, de termos professores generalizantes, considerando-se que professores deverão se submeter à ministração de aulas de conteúdos disciplinares alheios à sua formação originária, até mesmo para integralizarem sua carga horária de trabalho, além do que a Reforma prevê que qualquer pessoa, selecionada mediante um suposto "notório saber", possa ministrar aulas de conteúdo, dos quais não possua formação específica, prerrogativa já concedida, segundo a letra da MP, à área de Formação Técnica e Profissional. Viola-se a própria identidade profissional do docente, considerando-se que esta vai além do mero domínio dos conteúdos, compreendendo também o domínio da própria prática e saberes docentes na respectiva área de conhecimento do docente.

Vê-se, portanto, que o discurso governamental na direção de tentar convencer a sociedade de que se trata da implementação de um modelo educacional flexível, moderno, contextual e atraente aos alunos, resulta numa grande falácia. A Reforma implantada se choca com a Lei de Diretrizes e Bases da Educação Nacional e no Plano Nacional de Educação, principais instrumentos normativos norteadores gerais da educação, resultados de lutas sociais em prol de uma educação democrática e de qualidade. Na realidade, a Reforma representa um retrocesso de décadas em nossa histórica educacional, devendo deixar para as novas gerações de educando um déficit na qualidade de sua formação, oxalá a serem um dia supridas novamente, no caso de não se conseguir reverter a aprovação dessa Reforma no âmbito político.

A Reforma promove, ainda, uma exclusão social quanto aos filhos das classes trabalhadoras que possuem como única alternativa de acesso à educação escolar o período noturno. Considerando-se que a carga horária será 
INTER-LEGERE

A MEDIDA PROVISÓRIA 746/2016 E SUAS IMPLICAÇÕES PARA A PERMANÊNCIA E REDIMENSIONAMENTO DA SOCIOLOGIA NO CURRÍCULO DO ENSINO MÉDIO

Francisco Alencar Mota

Antonia Zeneide Rodrigues

ampliada, a fim de estabelecer o ensino integral, temos que ou as atividades correspondentes à carga horária estendida não contemplarão esses segmentos sociais, visto que se recorrem ao ensino noturno é porque trabalham durante 0 dia; ou essas atividades serão um "faz de conta", como aconteceu com a reforma de 1971. Registre-se que o ensino noturno abriga a grande maioria dos alunos da rede pública.

\section{CONCLUSÃO}

A história parece, em diversos momentos, retroceder, frustrando-nos quanto a uma velha insistência por parte dos que lutam por uma sociedade melhor, de que caminha rumo a um aprimoramento do processo civilizatório e do espírito humano. A Medida Provisória 746/2016, por todas as explanações no presente trabalho, a despeito dos discursos governamentais em contrário, serve de exemplo de um desse momentos de frustração, sobretudo em área tão estratégica para todas as demais dimensões da vida, quer seja voltada para o trabalho, a formação humanística ou o desenvolvimento econômico, como a área educacional. Em todas essas e outras dimensões da vida vê-se, a partir de uma simples leitura do texto da referida Medida Provisória, o quanto seus conteúdos depõem contra os discursos governamentais, representando um evidente retrocesso de décadas, fazendo-nos lembrar reformas educacionais passadas, como a do ensino de $2^{\circ}$ Grau, trazida pela lei 5.692/71 - a última até então, de cujo fracasso não se duvida hoje nem mesmo seus próprios idealizadores, o que dizer seus então simpatizantes e defensores.

Dentre os principais danos trazidos pela reforma hospedada na Medida Provisória 746/2016 está a própria formação do educando, privado agora de sequer poder refletir sobre si mesmo, a sociedade, o mundo, de maneira crítica e com autonomia, reduzido à perspectiva unidimensional de força de trabalho a ser aproveitado em postos de trabalho mal remunerado, para o que as 
A MEDIDA PROVISÓRIA 746/2016 E SUAS IMPLICAÇÕES PARA A PERMANÊNCIA E REDIMENSIONAMENTO DA SOCIOLOGIA NO CURRÍCULO DO ENSINO MÉDIO

Francisco Alencar Mota

Antonia Zeneide Rodrigues

certificações de estudos parciais previstas pela reforma não tem outra finalidade fora a de realizar este intuito, mais uma vez fazendo-nos reportar à falácia da reforma trazida pela lei 5.692/71.

Não é à toa que a Reforma em questão se coaduna com o PLS 193/2016, em trâmite no Congresso, concernente ao "Programa Escola sem Partido", que extingue do debate democrático temas tão relevantes para a formação cidadã e democrática, tais com os concernentes à participação política, aos direitos humanos, às diferenças e à própria democracia, esvaziando a natureza humana e social do educando, ao invés de promovê-la.

Por fim, a Reforma em questão reproduz, no âmbito do Ensino Médio, com implicações para os demais níveis e modalidades escolares, o sistema educacional do qual nos falou Florestan Fernandes, atrasado culturalmente, pavimentando, por outro lado, um caminho de reabertura da discussão sobre o papel da Sociologia nesse novo contexto políico, econômico e social, em situação relativamente de desvantagem. Mas nem por isso desprovida de novas expectativas quanto à reversão desse quadro, de sua afirmação enquanto disciplina científica autônoma e comprometida com os valores da igualdade social, da democracia e das diferenças.

\section{REFERÊNCIAS}

AZEVEDO, Fernando de. O Ensino e as Pesquisas Sociológicas no Brasil: problemas e orientações. In: BARREIRA, César. A Sociologia no Tempo: memória, imaginação e utopia. São Paulo: Cortez, 2003.

AZEVEDO, Gustavo Cravo de. Sociologia no Ensino Médio: uma trajetória político-institucional (1982-2008). 2014. 222 f. (Dissertação em Ciência Política) - Universidade Federal Fluminense, Rio de Janeiro, 2014.

BRASIL. Medida Provisória n. 746, de 23 de setembro de 2016. Institui a Política de Fomento à Implementação de Escolas de Ensino Médio em Tempo Integral, altera a Lei no 9.394, de 20 de dezembro de 1996, que estabelece as 
A MEDIDA PROVISÓRIA 746/2016 E SUAS IMPLICAÇÕES PARA A PERMANÊNCIA E REDIMENSIONAMENTO DA SOCIOLOGIA NO CURRÍCULO DO ENSINO MÉDIO

Francisco Alencar Mota

Antonia Zeneide Rodrigues

diretrizes e bases da educação nacional, e a Lei no 11.494 de 20 de junho 2007, que regulamenta o Fundo de Manutenção e Desenvolvimento da Educação Básica e de Valorização dos Profissionais da Educação, e dá outras providências. Diário Oficial da União, Brasilia, DF, 23 Set. 2016. Seção 1 Edição Extra, p. 1 a 2.

CARVALHO, Lejeune Mato Grosso de (org). Sociologia e Ensino em Debate: experiências e discussão de sociologia no ensino médio. ljuí: Editora Unijuí, 2004.

FERNANDES, Bernardo Gonçalves. Curso de Direito Constitucional.

Salvador, BA: Editora JusPodivm, 2014.

FERNANDES, Florestan. O Ensino de Sociologia na Escola Secundária Brasileira. In: I CONGRESSO BRASILEIRO DE SOCIOLOGIA. São Paulo, 1954, Anais da SBS, 2011. p. 89-106.

IANNI, Octávio (org). Florestan Fernandes: sociologia crítica e militante. São

Paulo: Editora Expressão Popular, 2004.

FERNANDES, Florestan. A Sociologia no Brasil. Petrópolis, 1976.

GHIRALDELLI Jr. Paulo. História da Educação. São Paulo: Cortez, 2000

PIRES, Antonio Fernandes. Direito Constitucional. Rio de Janeiro: Elsevier, 2013

ROMANELLI, Otaíza de Oliveira. História da Educação no Brasil, 19ª Ed.

Petrópolis,

SOARES, Eliane Veras. Florestan Fernandes: o militante solitário. São Paulo: Cortez, 1997. 